\title{
COMPARATIVE ANALYSIS OF STATION BLACKOUT ACCIDENT PROGRESSION IN TYPICAL PWR, BWR, AND PHWR
}

\author{
SOO-YONG PARK* and KWANG-IL AHN \\ Korea Atomic Energy Research Institute \\ 989-111 Daedeokdaero, Yuseong-gu, Daejeon, 305-353, Korea \\ "Corresponding author. E-mail : sypark@kaeri.re.kr
}

Received August 18, 2011

Accepted for Publication December 20, 2011

\begin{abstract}
Since the crisis at the Fukushima plants, severe accident progression during a station blackout accident in nuclear power plants is recognized as a very important area for accident management and emergency planning. The purpose of this study is to investigate the comparative characteristics of anticipated severe accident progression among the three typical types of nuclear reactors. A station blackout scenario, where all off-site power is lost and the diesel generators fail, is simulated as an initiating event of a severe accident sequence. In this study a comparative analysis was performed for typical pressurized water reactor (PWR), boiling water reactor (BWR), and pressurized heavy water reactor (PHWR). The study includes the summarization of design differences that would impact severe accident progressions, thermal hydraulic/severe accident phenomenological analysis during a station blackout initiated-severe accident; and an investigation of the core damage process, both within the reactor vessel before it fails and in the containment afterwards, and the resultant impact on the containment.
\end{abstract}

KEYWORDS : Accident Progression, Station Blackout, Severe Accident, MAAP Code, ISAAC Code

\section{INTRODUCTION}

Since the crisis at the Fukushima nuclear power plants, severe accident progression has been recognized as a very important area for accident management and emergency planning. The purpose of this study is to investigate the comparative characteristics of severe accident progressions among typical pressurized water reactors (PWR), boiling water reactors (BWR), and pressurized heavy water reactors (PHWR). The OPR 1000-like (ABB-CE type PWR), Peach Bottom-like (BWR/4 RCS with a MARK I Containment), and Wolsong1-like (CANDU6 type) plants were selected as reference plants of typical $1000 \mathrm{MWe}$ PWR, 1140MWe BWR, and 600 MWe PHWR, respectively.

The design parameters of these plants are quite different. Some of the major different design features of CANDU6 plant from other light water reactors, in terms of a severe accident, are that the plant adopts a dual primary heat transport system and has an additional amount of cooling water in the calandria vessel (calandria tank, CT) and calandria vault $(\mathrm{CV})$. Another feature is that the CT is always submerged in water because the $\mathrm{CV}$ is flooded during normal operation. The containment (reactor building, $\mathrm{R} / \mathrm{B}$ ) failure pressure of the CANDU6 plant is considerably lower than that of the typical PWR or BWR4/MARK-I. The containment vessel free volume of MARK-I is much smaller than that of the PWR or CANDU6 plant. Since there is no steam generator ( $\mathrm{SG}$ ) or passive cooling system, the amount of cooling water inventory in BWR4 is relatively less than in other plants. Meanwhile, the minimum available time of battery power against a station blackout (SBO) accident is different among the plant types: six hours for BWR4 and four hours for 1000MWe PWR. Therefore, plant responses against severe core damage scenarios like the Fukushima accident are expected to be much different. By identifying plant response signatures, the appropriate corrective actions can be developed as part of severe accident management.

An SBO scenario, where all off-site power is lost and the diesel generators (DGs) fail, is simulated as an initiating event of a severe accident sequence. All current generation reactors are designed to partially cope with an SBO. For the simulation of an SBO, all the emergency core cooling (ECC) systems, auxiliary feedwater (AFW) systems except for the turbine driven pump (TDP), and the containment spray are assumed to be inoperable for the 1000MW PWR. All ECC systems, moderator cooling systems, end-shield cooling systems (ESC), and local air coolers (LACs) are assumed to be inoperable to simulate the severe core damage case for the CANDU6 plant. All the ECC systems except for high pressure coolant injection (HPCI), reactor core isolation cooling (RCIC), reactor water cleanup, 
standby liquid control, low pressure coolant injection (LPCI), and core spray are assumed to be not working for the BWR4/MARK1 plant.

The thermal hydraulic and severe accident phenomenological analyses for the evaluation have been performed using the PWR and BWR versions of MAAP (Modular Accident Analysis Program) 4.06 [1] for the PWR and BWR4/MARK1 plants, respectively. On the other hand, ISSAC (Integrated Severe Accident Analysis Code for the CANDU Plants) 4.02[2] has been used for the CANDU6 plant. The ISAAC program has been developed based on MAAP4. Therefore, most of the basic thermal hydraulic and radiological models of those two computer codes are similar. Only the plant specific system models are different from each other. In the MAAP and ISAAC code, the plant system is divided into two regions: the reactor coolant system and the containment. The nodalization of the reactor coolant system is not defined by the user but modeled as fixed nodes. 14, 7, and 14 nodes are defined for PWR, BWR, and CANDU6, respectively. $[1,2]$ The containment is modeled not as a fixed compartmentalized structure but as an interconnection of compartments and flow paths. However, the code is not sensitive to the number of compartments. 6, 5, and 12 compartments are defined for PWR, BWR, and CANDU6, respectively.

In this paper, the important design parameters of the three plants are compared, the characteristics of a severe accident progression are then analyzed, and finally a summary and conclusions are presented. The analysis includes the evaluation of available time to the core uncovery, core melting start, reactor vessel or containment failure, and the estimation of the in-vessel hydrogen generation and molten corium-concrete interaction in the reactor cavity, calandria vault, or pedestal. The event timing of an SBO accident progression was focused on in this paper. Even though "time" is merely one of many aspects to be referred to for the comparison of the level of safety, the available time for recovery actions by operators would be a very important parameter in accident management. Symptom based accident management strategies can resolve most of the limitations of the event based approach by using the Critical Safety Functions and the Severe Challenge Status Tree. However these symptom based procedures also have their drawbacks. These limitations should be addressed and resolved. The main limitation is the lack of the time and lack of information about the prognosis of the event in time. Information of time available for the restoration action inside the plant is important for the optimum strategy onsite. Information of the time window before relevant off-site releases could be expected, if the restoration action is not successful, is important for regulatory authorities and the public. [3]

\section{COMPARISON OF DESIGN FEATURES}

This section briefly outlines the design of three plant types with special reference to their respective severe accident mitigation features. The design parameters of the 1000MW PWR, CANDU6, and BWR4/ MARK1 plants are summarized in Table 1 .

Table 1. Major Input Modelling Parameters of the 1000MW PWR, CANDU6, and BWR4/MARK1

\begin{tabular}{|c|c|c|c|c|}
\hline \multicolumn{2}{|c|}{ Design Parameter } & 1000MW PWR & CANDU6 & BWR4/MARK1 \\
\hline \multicolumn{2}{|c|}{ Plant Type } & PLWR & PHWR & BWR \\
\hline \multicolumn{2}{|c|}{ Power $\left(\mathrm{MW}_{\mathrm{th}}\right)$} & 2,815 & 2,140 & 3,293 \\
\hline \multirow{5}{*}{$\begin{array}{l}\text { Coolant } \\
\text { Inventory } \\
\left(10^{3} \mathrm{~kg}\right)\end{array}$} & Steam Generator & 134 & 151 & N/A \\
\hline & PHTS (RCS) & 215 & 108 & 252 \\
\hline & ECC Tanks (SIT) & 208 & 214 & N/A \\
\hline & Calandria & N/A & 216 & N/A \\
\hline & Calandria Vault & N/A & 500 & N/A \\
\hline \multirow{2}{*}{$\begin{array}{l}\text { Core Material } \\
\qquad\left(10^{3} \mathrm{~kg}\right)\end{array}$} & $\mathrm{UO}_{2}$ & 86 & 99 (Natural) & 159 \\
\hline & Zircaloy & 24 & 43 & 69.5 \\
\hline \multicolumn{2}{|c|}{ Mitigation System against SBO } & $\begin{array}{l}\text { TDP AFW with } \\
\text { Battery Power }\end{array}$ & Dousing Spray & $\begin{array}{l}\text { HPCI, RCIC with } \\
\text { Battery Power }\end{array}$ \\
\hline \multicolumn{2}{|c|}{ Reactor Cavity (Calandria Vault, Pedestal) Floor Area $\left(\mathrm{m}^{2}\right)$} & 62.54 & 54.20 & 29.17 \\
\hline \multicolumn{2}{|c|}{ Containment Free Volume $\left(\mathrm{m}^{3}\right)$} & 79,300 & 48,000 & 7,132 \\
\hline \multicolumn{2}{|c|}{ Containment Failure Pressure (MPa(g)) } & 1.236 & 0.416 & 1.020 \\
\hline
\end{tabular}




\subsection{MW PWR with Large Dry Containment}

The reactor uses pressurized water with a core thermal output of 2815 MWth. The reactor coolant system (RCS) consists of a reactor vessel and two independent primary coolant loops, each of which has two reactor coolant pumps (RCPs) and a steam generator. A pressurizer is connected to one of the loops, and safety injection lines are connected to each of the four cold legs and two hot legs.

The RCS operates at a nominal pressure of $15.51 \mathrm{MPa}$ and the system water mass without the pressurizer is about $2.15 \times 10^{5} \mathrm{~kg}$. The pressurizer has three safety valves to provide protection against over-pressurization. The opening set point is $17.24 \mathrm{MPa}$ and minimum blow-down reclosure pressure is $14.07 \mathrm{MPa}$, meaning the pressure of the RCS varies from 17.24 to $14.07 \mathrm{MPa}$ given the actuation of the safety valves.

Secondary heat removal is achieved by means of steaming and feeding the SGs. Feedwater may be supplied to the SGs using one of several pumps, for instance, main feedwater (MFW), startup feedwater, and auxiliary feedwater (AFW). However, AFW turbine driven pumps (TDPs) can be credited as a unique means of supplying feedwater in the SBO event. The AFW TDPs can provide feedwater until all station batteries, the capacity of which is a minimum of four hours, are depleted. The secondary steam can be removed via the main steam safety valves (MSSVs) or atmospheric dump valves (ADVs), where the ADVs need an operator action to open.

A safety injection system of the plants consists of four safety injection tanks (SITs) and high-pressure and lowpressure safety injection pumps. The SITs automatically discharge into the RCS if the RCS pressure decreases below the SIT pressure (4.31 MPa) during reactor operation. The total water mass of the SITs is about $2.08 \times 10^{5} \mathrm{~kg}$. Since the pressure of the RCS is maintained above the SIT injection set point in most transient accident sequences, the SIT injection occurs only after a vessel breach or other induced RCS failure. If the vessel has failed, the inventory of the SIT is injected into the reactor cavity. This water in the cavity precludes or mitigates concrete ablation with molten corium-concrete interaction (MCCI). As a large amount of water is injected into the cavity from the SIT via the reactor vessel, it takes a long period of time to dry out the cavity. This large water volume in the SITs delays the occurrence of the MCCI and gas generation in the cavity.

The plant has a large containment free volume $\left(79,300 \mathrm{~m}^{3}\right)$ capacity, which implies lower accident peak transient pressures and a longer time delay to failure for the containment building. According to a containment internal pressure capacity analysis performed for PSA [4], the median failure pressure is found to be $1.236 \mathrm{MPa}(\mathrm{g})$ in the hoop of the cylinder wall. The strong containment design combined with the large containment free volume results in very low probabilities of overpressure containment failures. Even when failure is inevitable due to a loss of containment heat removal, these aspects of the containment design cause the time to failure to be significantly longer, allowing more time for recovery actions.

The plant has a much larger cavity area $\left(62.54 \mathrm{~m}^{2}\right)$ and volume. The significance of the reactor cavity is related to the status of water availability and the ultimate disposition of the molten core after vessel breach. The presence of water affects the pressure loads at a vessel breach and debris coolability in the longer term. A geometric configuration allowing a shallow pool to form can result in a coolable configuration. If water is available on the cavity floor, a concrete attack can be mitigated. The flooded cavity increases the potential to preclude MCCI.

\subsection{CANDU6 Plant}

A CANDU6 is a heavy water-moderated, natural uranium-fuelled, pressurized heavy water reactor with a thermal output of about 2,140 MWth. The plant has two independent loops, containing 190 fuel channels in each loop and a total of four SGs with two SGs in each of the loops. The fission heat produced in the fuel is transferred to the light water in the secondary side of the SGs. 380 fuel channels are located in a horizontal position, inside a horizontal cylindrical calandria (vessel) made of stainless steel, which is surrounded by a low pressure heavy water moderator. The calandria vessel is housed in and supported by a light water-filled steel-lined concrete vault, called a calandria vault (CV), which provides thermal shielding. A significant quantity of heavy water surrounding the fuel acts as a heat sink to remove the decay heat after a reactor shutdown.

During the loss of Class III and Class IV power, secondary heat removal can be achieved by all means of steaming and feeding the SGs. The feedwater may be supplied using an emergency feedwater pump supplied from an emergency power system. However, the motor operated emergency feedwater pump is not available in an SBO event. The secondary steam can be removed via the main steam safety valves (MSSVs) or atmospheric steam dump valves (ASDVs), where the ASDVs need an operator action to open.

The heavy water moderator $\left(\sim 2.16 \times 10^{5} \mathrm{~kg}\right)$ in the calandria is a unique CANDU feature which provides a passive heat sink for some accident scenarios. The moderator is normally maintained at an average temperature of about $65^{\circ} \mathrm{C}$ by its cooling system which is capable of removing up to $100 \mathrm{MW}$ of heat. Over-pressure protection is provided by rupture discs at the top of calandria at the upper ends of four pressure relief pipes which are designed to provide an adequate discharge area for heavy water flow to the containment (boiler room) during a postulated simultaneous pressure tube/calandria tube rupture at full system pressure.

The CV is built of ordinary concrete and is filled with about $5.0 \times 10^{5} \mathrm{~kg}$ of light water which functions as a biological shield under normal operating conditions and as a passive heat sink under certain severe accident 
scenarios. For example, if hot dry debris is collected in the calandria bottom after core relocation, the $\mathrm{CV}$ water will remove the decay heat from the calandria through the calandria wall. In-vessel retention via external vessel cooling, which is considered to be an important accident management program in PWRs, is inherent in the CANDU design. The CV floor has an area of about $54.2 \mathrm{~m}^{2}$ which provides a significant spreading area for any potential core debris. As the distance between the calandria bottom and $\mathrm{CV}$ floor is about $2 \mathrm{~m}$, the corium (debris) pool formed in the vault will not touch the calandria. There are two layers of concrete below the CV floor (each $1.2 \mathrm{~m}$ thick). The thick concrete floor provides a significant time for ablation by hot molten debris.

As the CANDU6 has the above-mentioned additional water inventory, the role of a containment heat removal system such as dousing spray or local air coolers becomes important to control the containment pressure below the failure pressure. The dousing spray system is designed to limit the magnitude and duration of containment overpressure. The system is automatically initiated when the containment pressure exceeds $14 \mathrm{kPa}(\mathrm{g})$; however, the effect of dousing sprays on long term heat removal is not significant because the sprays are designed only for short term use. The containment design pressure of the modelled CANDU6 plant is $0.124 \mathrm{MPa}(\mathrm{g})$, the median value of a containment failure pressure is $0.416 \mathrm{MPa}(\mathrm{g})$, and the net total volume is approximately $48,000 \mathrm{~m}^{3}$ according to the reference [5]. At this pressure, the concrete on the wall starts cracking and the pressure is relieved.

\subsection{BWR4/MARK1 Plant}

The reference reactor of a BWR for this analysis is a 3,293 MWth BWR4/MARK1 [6]. It has four diesel generators (DGs) shared between the two units that are used to supply emergency AC power in the event that offsite power is lost. The DGs supply AC power to four trains of emergency systems for each unit simultaneously. In the event of an accident, there are several systems that can supply coolant injection to the core. Two systems are available to provide high pressure coolant injection: a high pressure coolant injection system (HPCI) and reactor core isolation cooling system (RCIC). Both systems use turbine-driven pumps with steam obtained from the reactor pressure vessel (RPV) and can only be used when the vessel pressure is high enough to run the turbines. Both the low pressure core spray system (LPCS) and low pressure coolant injection system (LPCI), which use the motor driven pumps, can provide coolant injection to the reactor vessel during accidents in which the system pressure is low. For additional backup sources of coolant injection, a firewater system can be used in some circumstances.

The Mark I BWR containment modeled in this analysis consists of a light-bulb shaped steel pressure vessel forming a drywell, which is connected to a suppression chamber (wetwell). The drywell and wetwell (or torus) communicate through passive vents (downcomers) in the suppression pool. The drywell and wetwell are made of steel, with an internal design pressure of $0.485 \mathrm{MPa}(\mathrm{g})$. The estimated failure pressure is $1.02 \mathrm{MPa}(\mathrm{g})$ [7], which is significantly higher than the design pressure. The free volumes in the drywell and wetwell are $4,777 \mathrm{~m}^{3}$ and $3,170 \mathrm{~m}^{3}$, respectively. The total volume of the wetwell (torus) is $7,132 \mathrm{~m}^{3}$, about half of which is occupied by water.

The safety relief valves (SRVs) and automatic depressurization system (ADS) play an important role in the sequence of events of station blackout. The SRVs vent steam from the reactor vessel into the wetwell. Each SRV is located on a steam header attached to the main steam lines leaving the reactor vessel. The plant has a total of 11 SRVs and two spring safety valves. The 11 SRVs have different opening and closing pressures; they open automatically when the opening pressure is reached. They also close automatically when the closing pressure in the vessel is reached. The lowest opening set pressures for relief mode and safety mode are 7.546 $\mathrm{MPa}$ and 8.235 $\mathrm{MPa}$, respectively.

To allow any of the low pressure injection systems to supply coolant to the vessel, the ADS is used to depressurize the reactor vessel. The ADS opens five SRVs simultaneously that discharge symmetrically into and around the torus below the suppression pool water level. Vessel depressurization by ADS actuation manually can be used to delay fuel heatup by 'steam-cooling'. The uncovered portions of the core can be cooled by the steam produced in the depressurization. The timing of the initiation of this depressurization for 'steam cooling' is very important in accident progression.

\section{MAJOR MODELING/ANALYSIS ASSUMPTIONS}

Several assumptions were made in the current analysis. These assumptions are either embedded in code as models with input control parameters, or they are assumed in the present analysis. Some of these assumptions should be addressed or relaxed in the future, if necessary. In this study, certain assumptions were made to generate an SBO accident sequence for application in the three types of plants.

Following a simultaneous loss of off-site and on-site AC power at $1000 \mathrm{MW}$ PWR, an immediate reactor trip occurs due to a loss of power to the control rod drive mechanism. After the reactor trip, the auxiliary feed water is delivered to one of two steam generators using a turbine driven pump. Since the analyzed sequence has no other mitigative operator actions and no power recovery, the heat is removed from the secondary side only by turbine driven AFW and MSSVs during the first four hours. Engineered safety features (ESF) such as high pressure safety injection (HPSI), low pressure safety injection (LPSI), containment spray (CS), and reactor containment fan cooler (RCFC) are not available. The only water available to cool the core on primary side is the initial 
reactor coolant system inventory. Even though there is a possibility of a temperature induced hot leg (or SG tube) rupture during the SBO sequence, it has not been modeled in this analysis due to the uncertainty of the phenomena. When a temperature induced rupture occurs, the accident progression will be delayed by the injection of safety injection tank inventory resulting from the depressurization of the RCS. For the MCCI calculation, the molten corium has been assumed to be spread onto the entire reactor cavity floor $\left(62.54 \mathrm{~m}^{2}\right)$, and the area of a containment floor outside reactor cavity, where the corium debris can be spread via high pressure melt ejection, is assumed to be $10.0 \mathrm{~m}^{2}$ [8].

For the CANDU6 plant, a station blackout (SBO) accident sequence has been modeled with the loss of class IV, and all back up power including loss of all on-site standby and emergency electric power supplies. Reactor shutdown is initiated immediately after accident initiation. The high/medium/low pressure emergency core cooling, crash-cooling function, shut-down cooling, moderator cooling, and shield cooling systems are not available. Operator intervention for the local air coolers is not credited. The passive containment dousing spray system is working. The main steam isolation valves (MSIVs) are not modeled, instead the turbine bypass valves and turbine stop valves are closed, which results in the same pressure behavior in the four SGs. Liquid relief valves (LRVs) and pressurizer relief valves are assumed to discharge the primary heat transport system (PHTS) inventory into the containment via the degasser condenser tank. There is an assumption that the relocated molten corium on the calandria bottom would be coolable in the CANDU6 plant because so-called in-vessel corium retention by external vessel cooling might be very feasible [9]. For the MCCI calculation, the molten corium has been assumed to be spread into the entire floor of CV (54.2 $\left.\mathrm{m}^{2}\right)$ [5].

For the SBO scenario in BWR4/MARK1, loss of all off-site and on-site AC power has been assumed, which leads to the loss of all active engineered safety features except the steam powered emergency core cooling systems: high pressure cooing injection (HPCI) and reactor core isolation cooling (RCIC). However, HPCI and RCIC require DC power for operation and would fail when the station batteries are depleted, which has been estimated to be six hours after the start of the accident. Operator intervention for the ADS is not credited, instead SRVs open automatically when the system pressure reaches the opening set pressure to release steam from the reactor vessel into the suppression pool. For the MCCI calculation, the molten corium has been assumed to be spread onto the entire pedestal floor $\left(29.17 \mathrm{~m}^{2}\right)$, and the floor surface area of the drywell where the area occupied by the corium debris is assumed to be $84 \mathrm{~m}^{2}$ [7]. A wet-well vent system is available that is expected to be effective in reducing fission products by scrubbing in the suppression pool. [10] In some scenarios, the containment fails by over pressurization before core damage. In such cases, the containment vent will lower the containment and reactor vessel pressure and enable additional injection for the core cooling. Then, a significant radioactive release can be avoided by releasing the containment gas that is not significantly contaminated yet. Also, venting through the suppression chamber (the torus) is a kind of "filtered vent" by utilizing the effect of pool scrubbing. The venting is a controlled release to prevent an uncontrolled release by containment failure. In order to prevent structural failure of the containment, the primary containment venting system can be used to obtain a controlled release of pressure and radionuclides from the containment. [6] The mitigation effects are not considered in this analysis.

\section{THERMAL HYDRAULIC AND SEVERE ACCIDENT PHENOMENOLOGICAL ANALYSIS}

The results of MAAP PWR/BWR and ISAAC simulation for the SBO scenario, where the calculations are continued to containment failure, are presented in this section. The summary of event occurrence times is represented in Table 2.

\subsection{MW PWR}

Plots of selected plant time parameter variables are depicted in Fig. 1. Following a simultaneous loss of offsite and on-site AC power, an immediate reactor trip occurs due to loss of power to the control rod drive mechanism. After the reactor trip, the pressure in the primary system (Fig. 1(a)) decreases slowly. During that time interval, AFW is delivered to SGs using the TDP. Since the sequence analyzed has no other mitigative operator action and no power recovery, heat is removed from the secondary side only by AFW, TDP, and MSSVs during the four hours of battery power supply. The only water available to cool the core in the primary side is the initial RCS inventory. The cooling water injection from four SITs is not available as long as the system remains at an elevated pressure.

The RCS pressure increases from 6.2 hours as the water level of SGs decreases (Fig. 1(b)), and reaches the PSV set point (17.24 MPa). The PSVs start open/close cycling at 7.3 hours (Fig. 1(a), Table 2). The water level in the vessel (Fig. 1(c)) continues to decrease due to the loss of RCS inventory through the PSVs, and the core becomes uncovered (water level decrease to $6.1 \mathrm{~m}$ ) at 8.5 hours (Table 2). The uncovered region of the fuel then heats up due to insufficient water/steam flow and onset of the zircaloy-steam reaction, and quickly rises to the fuel melting temperature at 10.2 hours (Fig. 1(d), Table 2). Sufficient steam passes through the core region to produce about $459 \mathrm{~kg}$ of hydrogen (Fig. 1(e)) from oxidation of the zircaloy $(43.8 \%)$. The molten core material relocates into the lower plenum and the reactor vessel eventually fails at 12.0 hours (Fig. 1(a), Table 2). 
At the time of reactor vessel failure, the RCS maintains an elevated pressure of about 15.7 MPa (Fig. 1(a)), which results in a high pressure melt ejection (HPME), causing molten debris dispersal out of the ruptured vessel into the cavity and surrounding compartments in the containment. About $18 \%$ of the corium is dispersed into the lower compartment and the rest is captured in the cavity. The inventory of four SITs is injected into the cavity (Fig. 1(f)) after the reactor vessel has failed, preventing a moltencorium concrete interaction (MCCI) until the water in the cavity has nearly dried out. The molten-corium starts to interact with the concrete 35 hours into the accident eventually ablating downward into the concrete to a depth of $3.64 \mathrm{~m}$ during the next 120 hours (Fig. 1(g)). The containment pressure increases due to the steam production from the water overlying the corium until the cavity dries out and due to the non-condensable gas generation from the MCCI phenomena (Fig. 1(f)). The pressure of the containment atmosphere reaches the pressure of hoop failure in the cylindrical wall of $1.236 \mathrm{MPa}(\mathrm{g})$ at 113.1 hours (Table 2).

\subsection{CANDU6 Plant}

A summary of the predicted timing of key events for the ISAAC calculation is represented in Table 2, and the responses of important parameters are shown in Fig. 2.

Following the postulated SBO scenario, the reactor is shut down and the core decay heat is transferred to the SGs. As a result, the SG secondary side boils off, discharging steam from the secondary side to the outside of the containment through the MSSVs. The SGs dry out at about 2.5 hours (Fig. 2(a)) and the PHTS pressure increases until it reaches the LRV set point (10.34 MPa) at 2.6 hours and oscillates at the relief valve set point (Fig. 2(b)), which finally results in fuel channel dryout. Subsequent heat up of the pressure tubes and calandria tubes at $\sim 10 \mathrm{MPa}$ of PHTS pressure results in the ballooning and rupture of a lead channel, causing a rapid blowdown of the PHTS coolant into the calandria (CT) at 4.1 hours (Fig. 2(c)). Since no moderator cooling and make-up is credited, the moderator level in the CT further decreases as a result of moderator boil off and causes the uncovery of the top fuel channels (Fig. 2(d)).

As fuel channel axial segments heat up and sag under gravity, they break up and form debris. During the sagging process the longitudinal total strain of the fuel channel increases [11]. The total strain will be concentrated between the fuel bundle junctions as the sagging increases and lead to wall-thinning at the junction region between the fuel bundles $[12,13]$. The calandria tube will perforate as a result, which will allow steam to enter the gap between the pressure tube and calandria tube. The fresh zircaloy surfaces in the gap between the pressure tube and calandria tubes are exposed to steam, and as a result the fuel channel temperatures will rapidly increase from the zircaloy-steam exothermic reaction and produce hydrogen. The total generated amount of hydrogen reaches about $751 \mathrm{~kg}$ (Fig. 2(e)). The higher hydrogen generation results from the large inventory of zircaloy. In the ISAAC model, the fuel channel fragments relocate to 'holding bins', where they are held temporarily as a 'suspended debris bed'. The suspended debris bed heats up further from the decay heat and from the $\mathrm{Zr} /$ steam exothermic reaction resulting in partial melting. Some of the molten material relocates at 6.4 hours (Table 2) from the suspended debris bed to the bottom of the CT (Fig. 2(f)), where it is quenched.

Following the core material relocation, the moderator in the CT is depleted at 12.8 hours (Table 2, Fig. 2(d)). The water in the calandria vault $(\mathrm{CV})$ cools the outer $\mathrm{CT}$ wall. Steam generated in the $\mathrm{CV}$ is released into the containment. Since no CV inventory make-up is credited

Table 2. Comparison of the Accident Progression of the 1000MW PWR, CANDU6, and BWR4/MARK1 for a Station Blackout Accident lunit: hours)

\begin{tabular}{|c|c|c|c|}
\hline EVENT & 1000MW PWR & CANDU6 & BWR4/MARK1 \\
\hline Battery power depleted & 4.0 & N/A & 6.0 \\
\hline PSV (or LRV) open & 7.3 & 2.6 & $<0.1$ \\
\hline SG dryout & 7.5 & 2.5 & N/A \\
\hline Core uncovery start & 8.5 & 3.7 & 7.7 \\
\hline Core melt start(PWR, BWR4) or fuel channel rupture (CANDU6) & 10.2 & 4.1 & 8.9 \\
\hline Corium relocation start & 11.7 & 6.4 & 11.8 \\
\hline RV (or Calandria vessel) dryout & 11.9 & 12.8 & 12.0 \\
\hline RV (or Calandria vessel) failure & 12.0 & 47.0 & 12.3 \\
\hline Containment (or $\mathrm{R} / \mathrm{B}$ ) failure & 113.1 & 28.2 & 17.9 \\
\hline
\end{tabular}


in this analysis, the $\mathrm{CV}$ water reaches saturation temperature at 17.5 hours. Since no local air-cooler is credited in the analysis, the containment pressure increases gradually and reaches the containment failure pressure of $0.416 \mathrm{MPa}(\mathrm{g})$ at 28.2 hours (Table 2, Fig. 2(g)). As long as the CV water covers the CT bottom, and by assuring that the heat flux at the CT/CV water boundary does not exceed the critical heat flux, the corium can be maintained in the CT [9].

Fig. 2(f) shows the terminal debris mass in the CT from the ISAAC analysis. The figure shows (1) the total debris bed mass including particulates (solid debris), corium crust, and molten corium in the calandria, (2) mass of particulates, (3) mass of molten corium, and (4) mass of the corium crusts (bottom, side and top surfaces). After

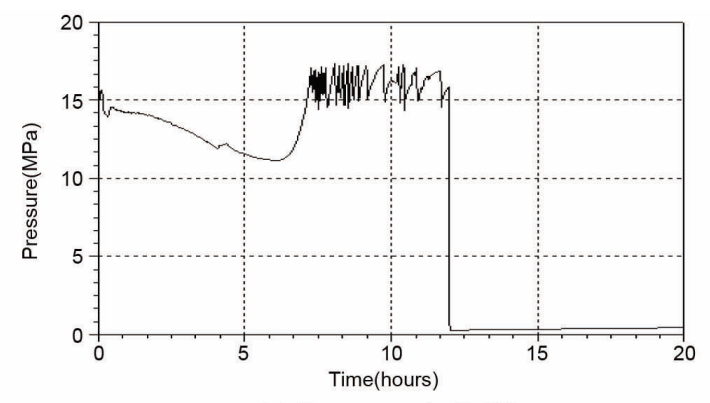

(a) Pressure in RCS

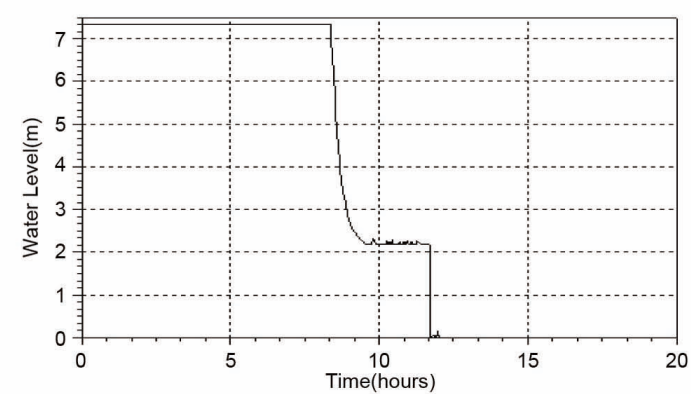

(c) Water Level in Reactor Vessel

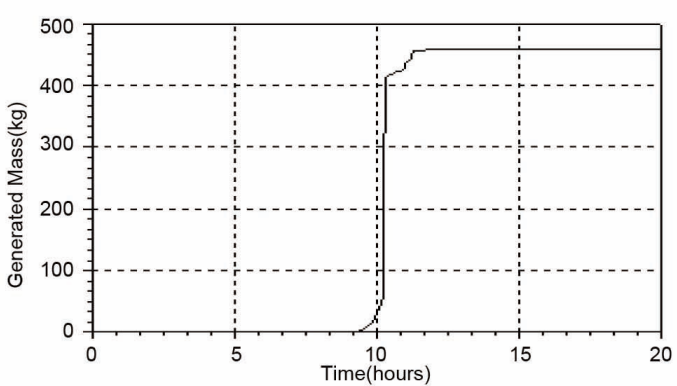

(e) Generated Hydrogen Mass in Vessel

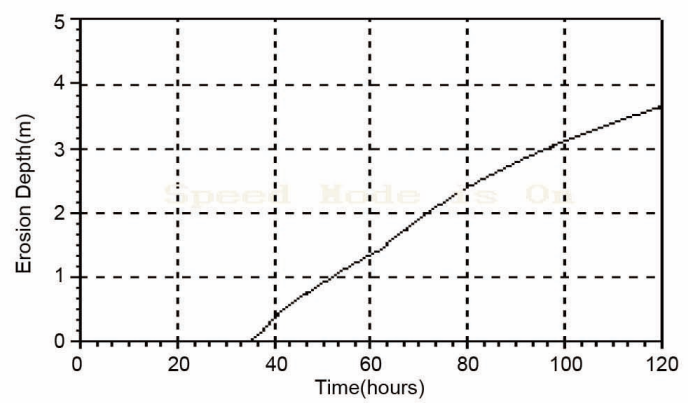

(g) Axial Erosion Depth in Reactor Cavity

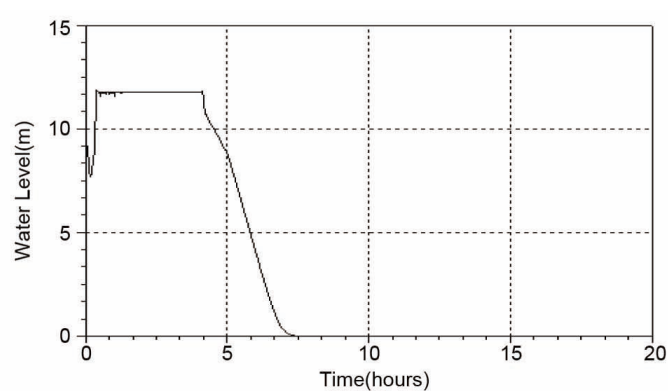

(b) Water Level in Steam Generator

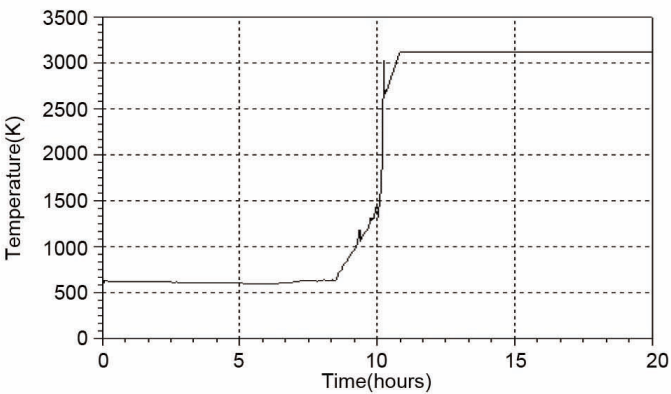

(d) Fuel Temperature in Hottest Core Node

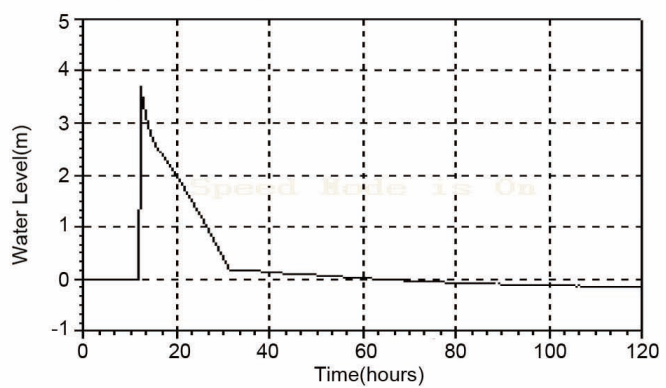

(f) Water Level in Reactor Cavity

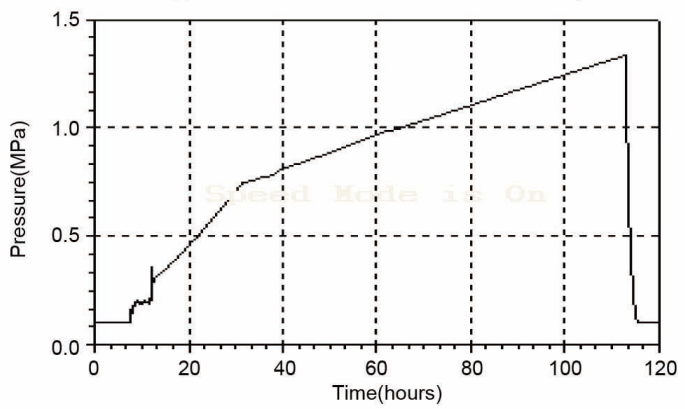

(h) Pressure in Containment

Fig. 1. Plant Parameter Behaviors during SBO Accident Sequence in 1000MW PWR 
the water in the CT is depleted, the core debris in the CT begins to heat up and eventually the solid debris melts to join the molten debris pool from about 13 hours. The molten debris pool is surrounded by a solid crust, which grows with time.

Since there is no CV make-up, the CV water level decreases to $2.5 \mathrm{~m}$ at about 46 hours (Fig. 2(d)), the CT bottom heats up rapidly and fails due to creep at 47.0 hours (Table 2). When the debris is relocated into the $\mathrm{CV}$ (Fig. 2(f)), it is cooled by the CV water. After the CV water is depleted, the molten-corium starts to interact with concrete 58 hours into the accident, eventually ablating into the concrete to a depth of $1.75 \mathrm{~m}$ at 120 hours from the accident initiation (Fig. 2(h)).

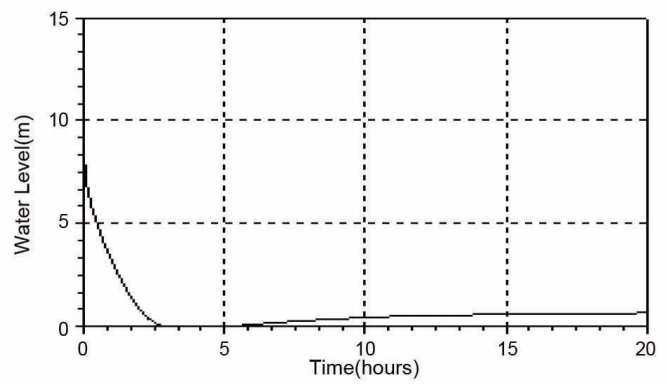

(a) Water Level in Steam Generator

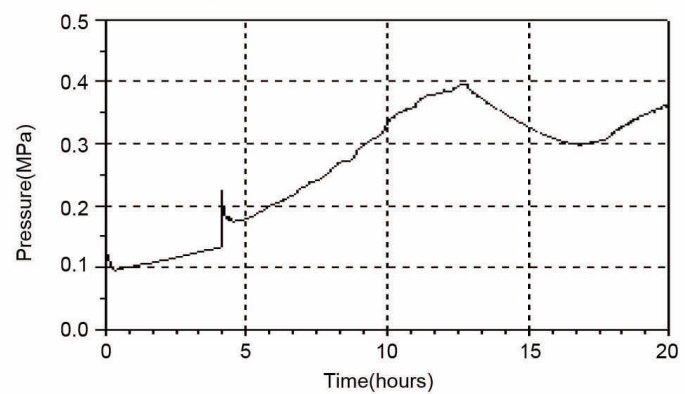

(c) Pressure in Calandria

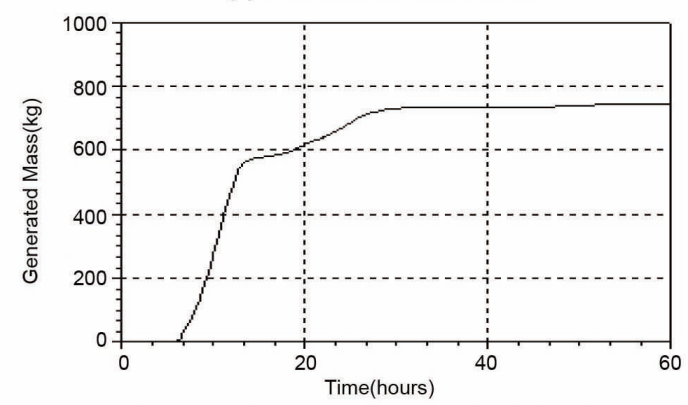

(e) Generated Hydrogen Mass in Calandria

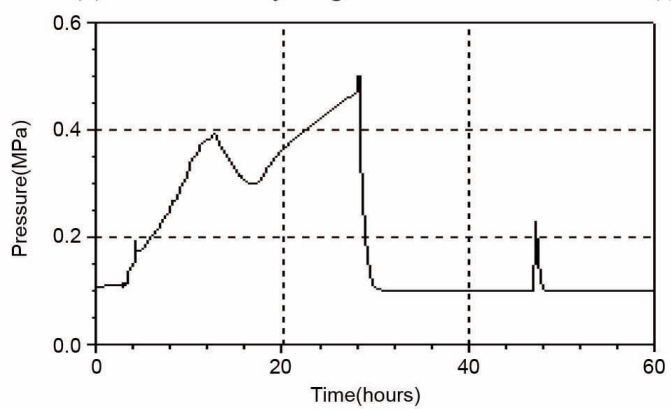

(g) Pressure in Containment

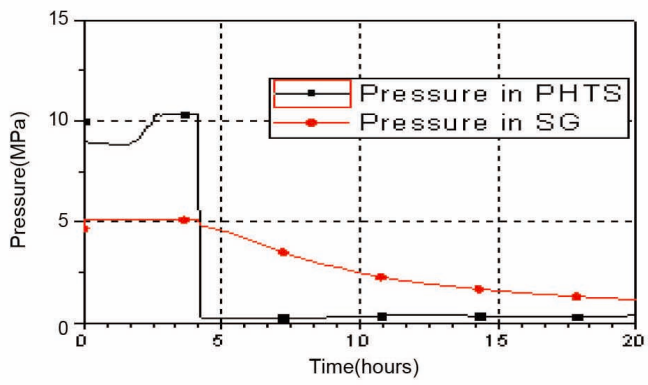

(b) Pressure in PHTS and SG

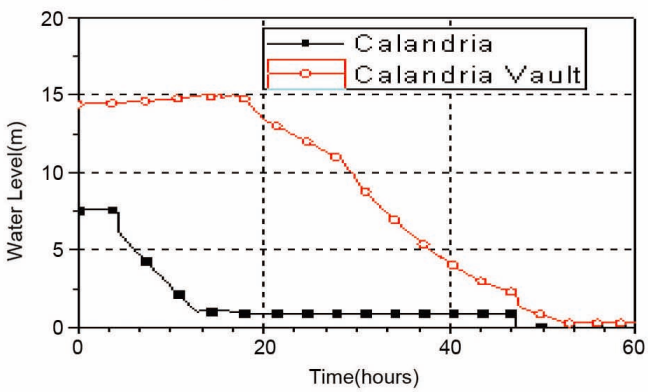

(d) Water Level in Calandria and Calandria Vault

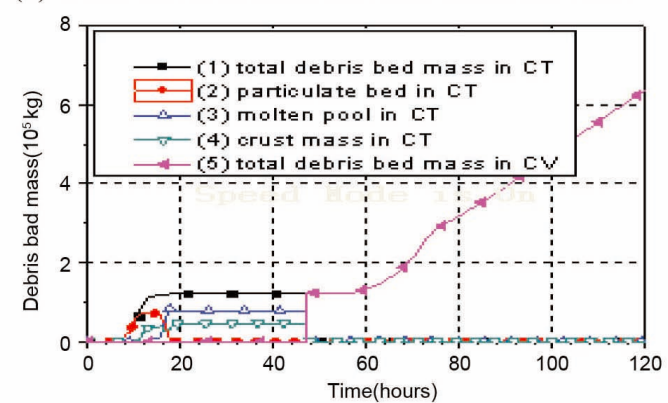

(f) Debris Bed Behavior in Calandria and Calandria Vault

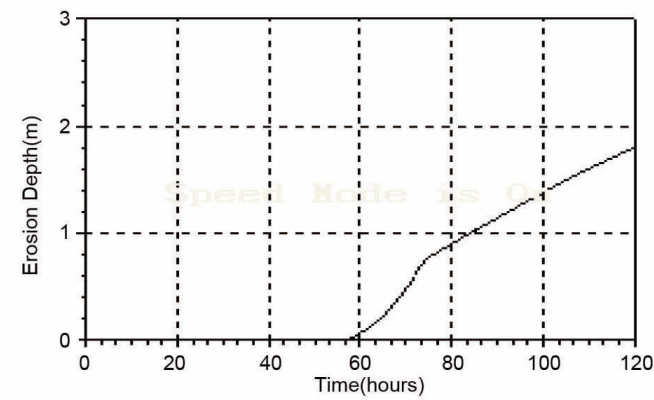

(h) Axial Erosion Depth in Calandria Vault

Fig. 2. Plant Parameter Behaviors during SBO Accident Sequence in CANDU6 Plant 


\subsection{BWR4/MARK1 Plant}

Table 2 summarizes the predicted timing of key events for the MAAP/BWR calculation, and the response of important in-vessel and ex-vessel parameters are shown in Fig. 3.

Following a simultaneous loss of off-site and on-site AC power, an immediate reactor trip occurs. The pressure remains approximately constant around the SRV set point due to the pressure-relieving operation (Fig. 3(a)). During an accident, steam from the vessel is directed through the SRVs and is discharged through a sparger into the suppression pool. The SRV releases steam into the wetwell as a relief mode until battery depletion and into the drywell as a safety mode after battery depletion.

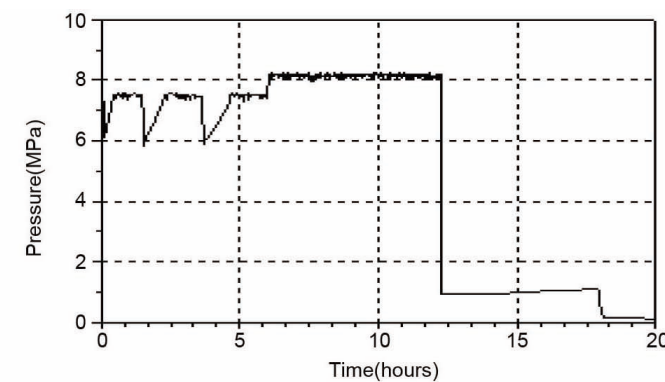

(a) Pressure in Reactor Vessel

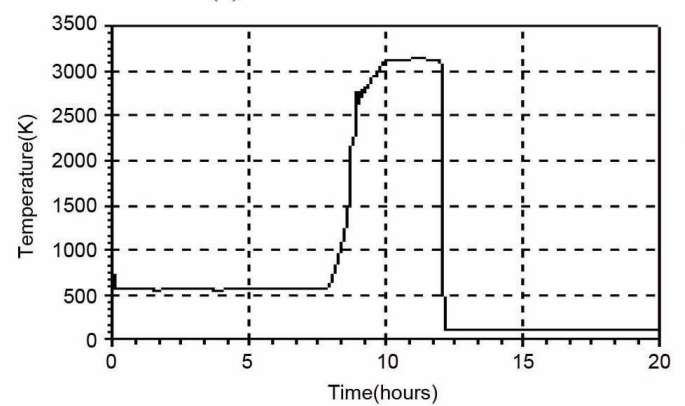

(c) Fuel Temperature in Hottest Core Node

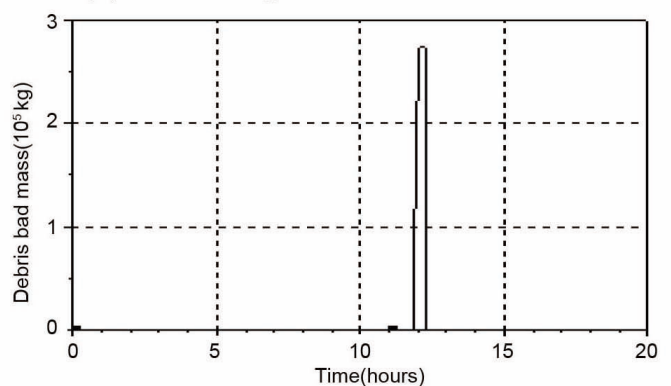

(e) Debris Bed Mass in Lower Plenum

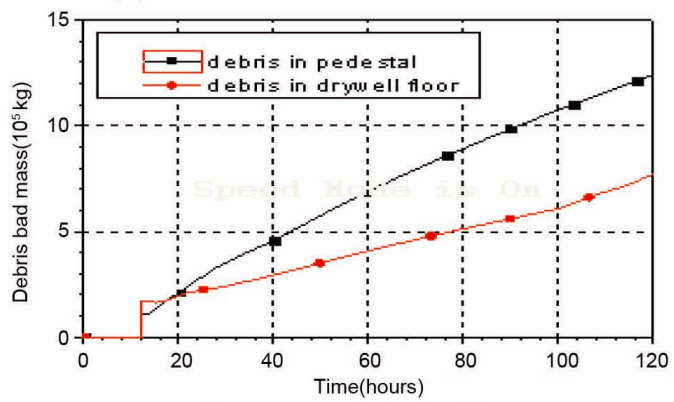

(g) Corium Mass in Pedestal and Drywell Floor (h) Axial Erosion Depth in Pedestal and Drywell Floor

Fig. 3. Plant Parameter Behaviors during SBO Accident Sequence in BWR4/MARK1

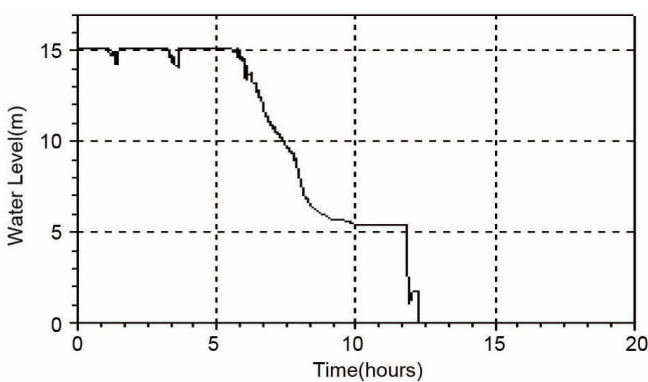

(b) Water Level in Reactor Vessel

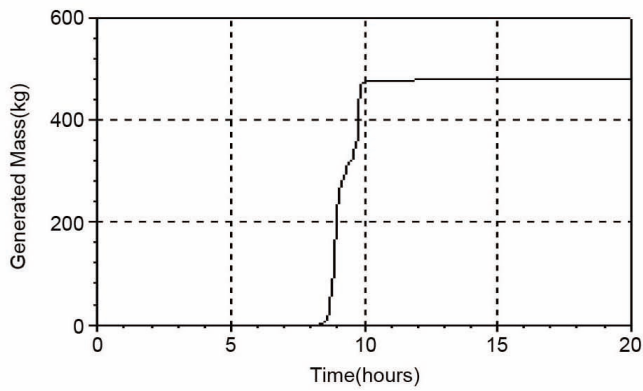

(d) Generated Hydrogen Mass in Vessel

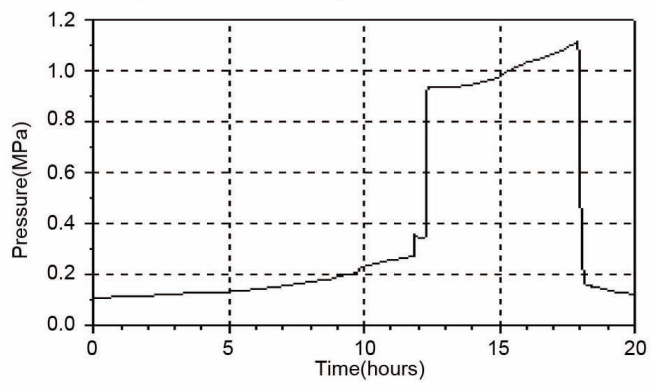

(f) Pressure in Drywell

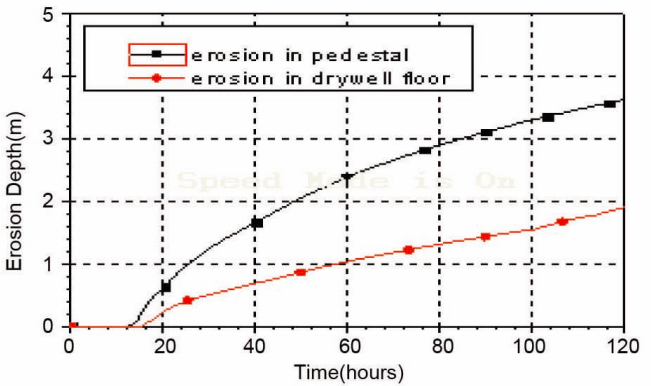


The steam is condensed in the pool and any non-condensable gases pass through the pool into the wetwell atmosphere. Vacuum breakers allow any overpressure in the wetwell to be relieved back into the drywell to keep the pressure difference less than 2 psig. SRV actuation releases the steam produced in the vessel by the decay heat of the fuel.

A BWR/4 plant has mitigation systems of HPCI and RCIC against a station blackout accident. The RCIC and HPCI systems are operable with no electric power other than battery power. During a station blackout, these systems are capable of providing decay heat removal by steam from the reactor. The systems are designed to inject substantial quantities of water into the reactor while it is at high pressure as long as battery power is available. The water level in the core and lower plenum maintains normal operation level by HPCI and RCIC operation with six hours of battery capacity (Fig. 3(b)). Since water is being vaporized after the loss of HPCI and RCIC due to battery depletion, the water level in the vessel decreases. Eventually, the water level in the vessel will drop below the top of the core at 7.7 hours (Table 2).

Once the core is uncovered, the fuel heats up due to insufficient water/steam flows, to the onset temperature of the zircaloy-steam reaction, and the temperature then increases to the fuel melting temperature at 8.9 hours (Fig. 3(c)). Fig. 3(d) shows the MAAP/BWR-predicted cumulative in-vessel hydrogen production, which reaches $481 \mathrm{~kg}$. Even though BWR/4 has the largest zircaloy inventory among the three types of plants, the hydrogen generation is not so great because the zircaloy oxidation of a fuel channel is only $4 \%$, whereas that of the cladding is about $27 \%$. The relocation of molten core material into the lower plenum starts at 11.8 hours (Fig. 3(e)) and the reactor vessel eventually fails at 12.3 hours (Table 2). The sharp drop in the reactor vessel pressure behavior in Fig. 3(a), hottest fuel node temperature in Fig. 3(c), and molten corium mass in Fig. 3(e) starting at 12.3 hours correspond to vessel failure and subsequent depressurization of the vessel.

The primary containment pressure history is presented in Fig. 3(f). It can be seen that failure of the reactor vessel leads to rapid pressurization of the primary containment. The containment pressure increases linearly due to the noncondensable gas generation from the MCCI phenomena. The pressure of the containment atmosphere reaches a failure pressure of $1.02 \mathrm{MPa}(\mathrm{g})$ at 17.9 hours (Table 2). At the time of reactor vessel failure, the vessel remains at an elevated pressure of about 8.2 MPa (Fig. 3(a), which results in a high pressure melt ejection (HPME), causing molten debris dispersal out of the ruptured vessel into the pedestal and surrounding drywell floor of the primary containment. About $170,000 \mathrm{~kg}$ of the molten corium has been dispersed into the drywell floor and the rest $(110,000 \mathrm{~kg})$ captured in the pedestal (Fig. 3(g)). The molten-corium starts to interact with concrete just after the reactor vessel failure in the pedestal and drywell floor simultaneously, eventually ablating into the concrete to a depth of $3.6 \mathrm{~m}$ and $1.9 \mathrm{~m}$, respectively, during 120 hours (Fig. 3(f)).

\section{SUMMARY AND CONCLUSIONS}

This paper focuses on the current understanding of the progression of a severe core damage accident for the typical PWR, BWR, and CANDU6 plants. The study includes a brief outline of the design differences that would impact an accident progression, and a thermal hydraulic/ severe accident phenomenological analysis during an SBO initiated severe accident. Furthermore, the analysis includes in-vessel hydrogen generation and MCCI, which are also important issues in severe accident phenomena of nuclear power plants.

Following the CANDU SBO accident, the core is uncovered after the SGs have dried out. Since there is no recovery action after an accident initiation, a fuel channel rupture (4.1 hours), corium relocation (6.4 hours), water dryout in the calandria (12.8 hours), containment (R/B) failure (28.2 hours), and CT failure (47.0 hours) occur sequentially in a CANDU6 plant. In a likely manner, the core melt start (10.2 hours), corium relocation (11.7 hours), reactor vessel failure (12.0 hours), and containment failure (113.1 hours) also occur in a 1000MW PWR. While, the core melt start (8.9 hours), corium relocation (11.8 hours), reactor vessel failure (12.3 hours), and containment failure (17.9 hours) occur consecutively in BWR4/MARK1.

Based on the ISAAC and MAAP calculations, the results show that the accident progression of a CANDU6 type reactor until corium relocation is considerably earlier than those for PWR or BWR4. This results from the design differences among the three plants. As stated above, the 1000MW PWR is equipped with turbine driven AFW systems and MSSVs, which can provide a secondary feed and bleed function for the SBO scenario using battery power. The BWR4/MARK1 plant has mitigation systems of HPCI and RCIC against an SBO accident. The systems are operable with no electric power other than battery power. They are designed to inject substantial quantities of water into the reactor while it is at high pressure through TDP.

On the other hand, the failure time of CT in CANDU6 is greatly delayed compared to the others. The delay is due to the additional cooling water in the CT and CV, and the lower volumetric decay heat power of the molten corium on the CT bottom. A smaller power, 600MWe, was assumed for the CANDU6 case, and it should give a significant influence on the result. Moreover, it has a very large heat transfer area due to the outside water of the CV through the vessel wall. Another advantage, in terms of calandria integrity for the CANDU6 plant, is that the system always maintains a low pressure at the time of a 
CT failure since the rupture disks are opened during the moderator evaporation. These increase the feasibility of the in-vessel corium retention through external vessel cooling. In contrast with $\mathrm{CT}$ integrity, the calculation results show that the containment failure of a CANDU6 plant occurs considerably earlier than that of a PWR due to the lower failure pressure of the containment $(\mathrm{R} / \mathrm{B})$.

The most vulnerable design in terms of containment integrity is a MARK-I type plant, and a failure occurs much earlier due to a small containment volume. Based on these calculations, CANDU6 has an advantage in maintaining its calandria integrity, and a 1000MW PWR has an advantage in its containment integrity during an SBO accident. However, in the BWR analysis, both HPCI and RCIC were assumed to stop after the battery depletion. There is a possibility that HPCI is "fail as is" and kept open when the battery becomes dead. If it is the case, the result would be very different. Moreover, a proper mitigative operation of the vent systems or alternative water injection to the reactor vessel using the residual heat removal line of MARK-I type plant have potential to delay or prevent the containment failure.

The event timing of an SBO accident progression was focused on in this paper. However, "time" is merely one of many aspects to be referred for the comparison of the level of safety. An overall comparison of the level of safety needs more carefully constructed overall risk profiles, i.e. both the probabilities and consequences for an adequate spectrum of scenarios. The limitations of this analysis also result from the uncertain severe accident phenomena, for example hydrogen detonation or combustion, high pressure melt ejection, steam explosion, molten core concrete interaction, temperature-induced pipe break, which need more a mechanistic approach. Uncertainties are inherently very large for an analysis of severe accident phenomena. Also, an assessment that relies on one computer code is not necessarily reliable in an absolute manner though relative parametric comparison on a similar basis would be very useful.

\section{ABBREVIATION}

ADS automatic depressurization system

ADV atmospheric dump valve

AFW auxiliary feedwater

ASDV atmospheric steam dump valve

BWR boiling water reactor

CT calandria tank (calandria, calandria vessel)

CV calandria vault

DG diesel generator

ECC emergency core cooling

ESC end-shield cooling system

HPCI high pressure coolant injection

HPME high pressure melt ejection

HWR heavy water reactor

LAC local air cooler
LPCI low pressure coolant injection

MCCI molten corium-concrete interaction

MFW main feedwater

MSIV main steam isolation valve

MSSV main steam safety valve

PHTS primary heat transport system

PWR pressurized water reactor

$\mathrm{R} / \mathrm{B}$ reactor building (containment)

RCIC reactor core isolation cooling

RCP reactor coolant pump

RCS reactor coolant system

SBO station blackout

SG steam generator

SIT safety injection tank

SRV safety/relief valve

TDP turbine driven pump

\section{ACKNOWLEDGEMENTS}

This work was performed under the Mid- \& Longterm Nuclear R\&D Program sponsored by the Korea Ministry of Education, Science and Technology (MEST).

\section{REFERENCES}

[ 1 ] EPRI, "Modular Accident Analysis Program," (1994).

[2 ] KAERI, "Development of Computer Code for Level 2 PSA of CANDU Plant," Korea Atomic Energy Research Institute, KAERI/RR-1573/95, (1995).

[ 3 ] NEA/CSNI, " Recent Developments in Level 2 PSA And Severe Accident Management", NEA/CSNI/R(2007)16, November, (2007)

[4] Korea Electric Power Co., "Ulchin Unit 3\&4 Final Probabilistic Safety Assessment Report," Volume 5, (1997).

[ 5 ] KAERI, "ISAAC 4.02 Parameter File of Wolsong-1 Plant (CANDU-6)," Korea Atomic Energy Research Institute, (2008).

[6] USNRC, "Evaluation of Severe Accident Risks: Peach Bottom, Unit 2," NUREG CR-4551, SAND86-1309, Vol.4, Rev.1. December, (1990).

[ 7 ] EPRI, "Peach Bottom-like Sample Parameter File for MAAP 4.06 (BWR/4 RCS with a MARK I Containment)," Provided for MAAP User's Group, (2006).

[ 8 ] KAERI, "Ulchin Unit 3\&4 Parameter File for MAAP 4.06 (PWR with Large Dry Containment)," Korea Atomic Energy Research Institute, (2007).

[9] S.Y. Park et al, "An Investigation of an In-vessel Corium Retention Strategy for the Wolsong Pressurized Heavy water Reactor," Nuclear Technology, Vol.158, p. 109-115, April, (2007).

[10] Nuclear Safety Commission of Japan, "Accident Management for Severe Accidents at Light Water Power Reactor Installations", NSCRG:L-AM-II.01, May, (1992)

[11] P.M. Mathew, T. Nitheanandan, and S.J. Bushby, "Severe Core Damage Accident Progression within a CANDU 6 Calandria Vessel", AECL.

[12] P.M. Mathew, W.C.H. Kupferschmidt, V.G. Snell, and M. Bonechi, "CANDU-Specific Severe Core Damage Accident Experiments in Support of Level 2 PSA", Proceedings of 
PARK et al., Comparative Analysis of Station Blackout Accident Progression in Typlcal PWR, BWR, and PHWR

16th International Conference on Structural Mechanics in Reactor Technology, SMiRT 16, Washington DC, August 12-17, (2001)

[13] P.M. Mathew, A.J. White, V.G. Snell, and M. Bonechi,
"Severe Core Damage Accident Analyses and Experiments for CANDU Applications", Proceedings of 17th International Conference on Structural Mechanics in Reactor Technology, SMiRT 17, Prague, August 17-22, (2003). 